\title{
$\beta$-Cyclodextrin and oleic acid increase levels of dopamine and potentiates oxidative damage in young and adult rat brain
}

\author{
David Calderón Guzmán ${ }^{1}$, Norma Osnaya Brizuela ${ }^{1}$, Maribel Ortiz Herrera², Hugo Juárez Olguín ${ }^{3 *}$, \\ Armando Valenzuela Peraza ${ }^{1}$ and Gerardo Barragán Mejía ${ }^{1}$
}

\begin{abstract}
Background: Cyclodextrins are active pharmaceutical ingredients to treat neurological diseases by reducing neurotoxicity. The aim of this study was to test if combined consumption of $\beta$-cyclodextrin (BCD) and Oleic acid $(\mathrm{OA})$ potentiates brain antioxidant protection.

Methods: Four groups of young Wistar rats, grouped in 6 animals each, were treated as follows: Group (G) 1, saline solution 0.9\% (control); G2, BCD (0.7 g/kg); G3, OA (15 m/ $/ \mathrm{kg})$; G4, BCD + OA. The same design was assayed for groups of adult rats. Treatments were daily administered by oral means for five consecutive days. On the last day of administration, brains of the animals were extracted to measure dopamine, 5-HIAA, glutathione (GSH), ATPase, Lipoperoxidation and $\mathrm{H}_{2} \mathrm{O}_{2}$.

Results: Oleic acid and $\beta$-cyclodextrin upgraded the levels of dopamine, 5-HIAA and lipid peroxidation and downgraded the concentrations of $\mathrm{GSH}$ and $\mathrm{H}_{2} \mathrm{O}_{2}$ in cortex, hemispheres (striatum) and cerebellum/medulla oblongata regions.

Conclusions: The results of the present study suggest that combined use of oleic acid and $\beta$-cyclodextrin may increase oxidative damage in brain regions and promote alteration in dopamine and 5-HIAA amines and hence, constitutes health risks among age of subjects.
\end{abstract}

Keywords: Brain, Dopamine, Oleic acid, $\beta$-Cyclodextrin, Oxidative damage

\section{Background}

Cyclodextrins (CDs) are a group of nontoxic oligosaccharides that is widely used as drug excipients and protein stabilizers. CDs have also been found to reduce the neurotoxicity [1], but also they are active pharmaceutical ingredients to treat neurological diseases [2]. Neurological disorders suggest increase in intracellular $\mathrm{Ca}^{2+}$ concentrations leading to an increase in the formation of reactive oxygen (ROS) and nitrogen (RNS) species by lethal pathways [3]. In neurodegenerative disorders, oxidative stress provokes mitochondrial alterations and DNA damage [4]. It has been found that brain aging is accompanied by a

\footnotetext{
* Correspondence: juarezol@yahoo.com; adrianos27@hotmail.com ${ }^{3}$ Laboratorio de Farmacología, INP. Facultad de Medicina, Universidad Nacional Autónoma de México, Avenida Imán N 1, 3rd piso Colonia Cuicuilco CP, 04530 Mexico City, Mexico

Full list of author information is available at the end of the article
}

decrease in mitochondrial function [5]. However this damage can be treated with R- $\alpha$-lipoic acid (R-LA) which is a cofactor of mitochondrial enzymes and a very strong antioxidant [6].

Nitric oxide is a good neuromodulator however an extra amount of it may lead to cell damage by oxidative stress or by decreasing reduced glutathione levels via nitroso-glutathione (NOGSH) formation within the cell [7]. Since free radicals are known to damage cell components [8], mainly plasma membrane lipids [9], the central nervous system (CNS) is particularly susceptible and extremely dependent on the amount of antioxidants, especially during development, when brain metabolism and growth rates are high [10], and regulates energy and glucose homeostasis by acting on hypothalamic neuro circuits and higher brain circuits such as the dopaminergic system [11]. Brain plasma membrane phospholipids are in 
close contact with structural proteins embedded in the lipid bilayer [12], through which the ionic interchange occurs by the action of $\mathrm{Na}^{+}, \mathrm{K}^{+}$ATPase that stimulates $\mathrm{Na}^{+}$ and $\mathrm{K}^{+}$flow [13]. The inhibition of $\mathrm{Na}^{+}, \mathrm{K}^{+}$ATPase activity induces excitatory amino acids release within the CNS [14]. The purpose of the present study was to compare the combined effect of $\beta$-cyclodextrin (BCD) and oleic acid (OA) on selected oxidative stress markers and the levels of dopamine in brain regions of young and adult rat.

\section{Methods}

Four groups of Wistar rats, grouped in 6 animals each, were treated as follows: Group (G) 1, saline solution $0.9 \%$ (control); G2, BCD (7 g/kg); G3, OA (15 ml/kg); G4, BCD $+\mathrm{OA}$. The same design was assayed for groups of adult rats. Treatments were orally administered for 5 days. Animals were maintained in a mass air displacement room with a 12-h light: 12 -h dark cycle at $22 \pm 2{ }^{\circ} \mathrm{C}$ with a relative humidity of $50 \pm 10 \%$. Balanced food (Rodent diet 5001) and drinking water were given to the animals ad libitum. In the fifth day of the treatment, the rats were sacrificed by decapitation $60 \mathrm{~min}$ after receiving the last dose, and their brains were extracted and put in $\mathrm{NaCl}$ $0.9 \%$ at $4{ }^{\circ} \mathrm{C}$, idem. Animal experiments were carried out under strict compliance with the Guidelines for Ethical Control and Supervision in the Care and Use of Animals and all experimental procedures were done following national and international rules.

The brains were dissected in cortex, hemispheres (striatum) and cerebellum/Medulla oblongata in 5 volumes of $0.05 \mathrm{M}$ TRIS- $\mathrm{HCl}, \mathrm{pH} 7.4$ and used to evaluate ATPase activity and $\mathrm{H}_{2} \mathrm{O}_{2}$ level. An aliquot was obtained and homogenised in $0.1 \mathrm{M}$ of perchloric acid $\left(\mathrm{HClO}_{4}\right)$ $(50: 50 \mathrm{v} / \mathrm{v})$, for the evaluation of reduced glutathione (GSH), dopamine, and 5-HIAA concentrations.

\section{Measurement of dopamine (DA)}

The levels of DA were measured in the supernatant of tissue homogenized in $\mathrm{HClO}_{4}$ after centrifugation at $9000 \mathrm{rpm}$ for $10 \mathrm{~min}$ in a microcentrifuge (Hettich Zentrifugen, model Mikro 12-42, Germany), with a version of the technique reported by Calderon et al. [15]. An aliquot of the $\mathrm{HClO}_{4}$ supernatant, and $1.9 \mathrm{~mL}$ of buffer $(0.003 \mathrm{M}$

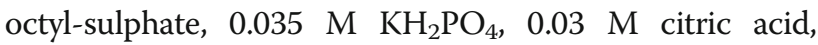
$0.001 \mathrm{M}$ ascorbic acid), were placed in a test tube. The mixture was incubated for $5 \mathrm{~min}$ at room temperature in total darkness, and subsequently, the samples were read in a spectrofluorometer (Perkin Elmer LS 55, England) with $282 \mathrm{~nm}$ excitation and $315 \mathrm{~nm}$ emission lengths. FL Win Lab version 4.00.02 software was used. Values were calculated from a previously standardized curve and reported as $\mu \mathrm{M} / \mathrm{g}$ of wet tissue.

\section{Measurement of 5-hydroxyindol acetic acid (5-HIAA)}

5-HIAA levels were measured in the supernatant of tissue homogenized in $\mathrm{HClO}_{4}$ after centrifugation at $9000 \mathrm{rpm}$ for $10 \mathrm{~min}$ in a microcentrifuge (Hettich Zentrifugen, model Mikro 12-42, Germany), with a modified version of the technique reported by Beck et al. [16]. An aliquot of the $\mathrm{HClO}_{4}$ supernatant and $1.9 \mathrm{ml}$ of acetate buffer $0.01 \mathrm{M} \mathrm{pH} 5.5$ were placed in a test tube. The mixture was incubated for $5 \mathrm{~min}$ at room temperature in total darkness, and subsequently, the samples were read in a spectrofluorometer (Perkin Elmer LS 55, England) with $296 \mathrm{~nm}$ excitation and $333 \mathrm{~nm}$ emission lengths. The FL Win Lab version 4.00 .02 software was used. Values were inferred in a previously standardized curve and reported as $\mathrm{nM} / \mathrm{g}$ of wet tissue.

\section{Measurement of reduced glutathione (GSH)}

GSH levels were measured from the homogenised tissue of the supernatant of the perchloric acid obtained after centrifuging at $9000 \mathrm{rpm}$ during $5 \mathrm{~min}$ (Mikro 12-42, Germany centrifuge) using a modified method of Hissin and Hilf [17]. $1.8 \mathrm{~mL}$ phosphate buffer $\mathrm{pH} 8.0$ with EDTA $0.2 \%, 20 \mu \mathrm{L}$ aliquot of the supernatant, and $100 \mathrm{~mL}$ of ortho-phthaldehyde (OPT) $1 \mathrm{mg} / \mathrm{mL}$ in methanol were poured in a test tube, and the mixture was incubated for $15 \mathrm{~min}$ at room temperature in absolute darkness. At the end of incubation, the samples were read spectrofluorometrically (PERKIN ELMER LS 55), with excitation and emission wavelengths of 350 and $420 \mathrm{~nm}$ respectively. FL Win Lab version 4.00 .02 software was used. Values were inferred from a previously standardised curve and expressed as $\mathrm{nM} / \mathrm{g}$.

\section{Measurement of lipid peroxidation (Tbars)}

Thiobarbituric acid reactive substances (Tbars) determination was carried out according to the method of Gutteridge and Halliwell [9], as follows: Each tissue sample was homogenized in $3 \mathrm{~mL}$ of phosphate buffer $\mathrm{pH}$ 7.4, from which $0.5 \mathrm{~mL}$ aliquot was taken and added to $1.5 \mathrm{~mL}$ of thiobarbituric acid (TBA) solution containing TBA $(1.25 \mathrm{~g})$, trichloroacetic acid $(40 \mathrm{~g})$ and concentrated $\mathrm{HCl}$ $(6.25 \mathrm{~mL})$ dissolved in $250 \mathrm{~mL}$ deionised water. The whole mixture was heated to water boiling point for $30 \mathrm{~min}$ (Thermomix 1420). Samples were then put in an ice bath for $5 \mathrm{~min}$ and then centrifuged at $3000 \mathrm{~g}$ for $15 \mathrm{~min}$ (Sorvall RC-5B Dupont). Supernatant absorbance was spectrophotometrically read in a three-set scheme at $532 \mathrm{~nm}$ (He入ios- $\alpha$, UNICAM). The concentration of malondialdehyde (MDA) was calculated by the absorbance coefficient of MDA-TBA complex $\left(1.56 \times 10^{5} \mathrm{M}^{-1} \mathrm{~cm}^{-1}\right)$. Tbars concentration was expressed as malondialdehyde $\mu$ moles per gram of wet tissue. 


\section{Measurement of total ATPase}

The activity of ATPase was assayed according to the method proposed by Calderón et al. [18]. $1 \mathrm{mg}$ (10\%) $w / v$ of homogenised brain tissues in tris- $\mathrm{HCl} 0.05 \mathrm{M} \mathrm{pH} 7.4$ was incubated for $15 \mathrm{~min}$ in a solution containing $3 \mathrm{mM} \mathrm{MgCl}$, $7 \mathrm{mM} \mathrm{KCl}$, and $100 \mathrm{mM} \mathrm{NaCl}$. To this was added $4 \mathrm{mM}$ tris-ATP and incubated for another $30 \mathrm{~min}$ at $37{ }^{\circ} \mathrm{C}$ in a shaking water bath (Dubnoff Labconco). $100 \mu \mathrm{L} 10 \%$ trichloroacetic acid $w / v$ was used to stop the reaction and samples were centrifuged at $100 \mathrm{~g}$ for $5 \mathrm{~min}$ at $4{ }^{\circ} \mathrm{C}$. Inorganic phosphate (Pi) was measured in triplicates using one supernatant aliquot as proposed by Fiske and Subarrow [19]. Supernatant absorbance was read at $660 \mathrm{~nm}$ in a Helios- $\alpha$, UNICAM spectrophotometer and this absorbance was then expressed as $\mathrm{mM} \mathrm{Pi} / \mathrm{g}$ wet tissue per min.

\section{Measurement of $\mathrm{H}_{2} \mathrm{O}_{2}$}

The determination of $\mathrm{H}_{2} \mathrm{O}_{2}$ was made using the modified technique of Asru [20]. Each brain region (cortex, striatum, cerebellum/medulla oblongata) was homogenized in $3 \mathrm{~mL}$ of tris- $\mathrm{HCl} 0.05 \mathrm{M} \mathrm{pH} 7.4$ buffers. From the diluted homogenates, $100 \mu \mathrm{l}$ was taken. $1 \mathrm{~mL}$ of potassium dichromate solution $\left(\mathrm{K}_{2} \mathrm{Cr}_{2} \mathrm{O}_{7}\right)$ was added to the homogenates. The mixtures were heated to boiling point for $15 \mathrm{~min}$ (Thermomix 1420). The samples were later placed in an ice bath for $5 \mathrm{~min}$ and were centrifuged at $3000 \mathrm{~g}$ for $5 \mathrm{~min}$ (Sorvall RC-5B Dupont). The absorbances of the floating were read in triplicate at

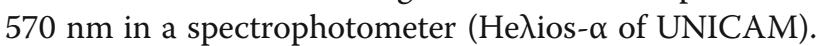
The concentration of $\mathrm{H}_{2} \mathrm{O}_{2}$ was expressed in $\mu$ Moles.

\section{Statistical analysis}

Analysis of Variance (ANOVA) or Kruskal-Wallis tests were used with their corresponding contrasts, and previous variance homogeneity comparison. Values restricted to $p<0.05$, were considered statistically significant [21]. JMP Statistical Discovery from SAS version 8.0 software was used.

\section{Results}

\section{General results}

The statistical analysis of the data unveiled significant differences between the control group and the treated groups in all brain regions and for all the indicators. With the exception of GSH and $\mathrm{H}_{2} \mathrm{O}_{2}$ (Figs. 3 and 5) the concentrations of the different indicators were lower for both adult and young animals in the control group when compared with the experimental groups.

\section{Levels of 5HIAA}

\section{Adult animals}

In the control group the concentration of 5HIAA was four times lower than those observed in the treated groups. On comparing the concentrations of the indicator between the experimental groups, it was observed that in the cortex there was a significant decrease in the group treated with the combination of cyclodextrin + oleic acid when compared with the group that received only oleic acid. In the hemispheres, the significant difference was between the groups that received administration of cyclodextrin and cyclodextrin + oleic acid. With regard to cerebellum/ medulla oblongata region, a decrease in the concentration of HIAA was observed in the cyclodextrin + oleic acid group when compared with the groups that received only cyclodextrin or oleic acid.

\section{Young animals}

By comparing the concentrations of 5HIAA among the experimental groups, a significant increase was observed in the cortex of the group that received a combination of cyclodextrin + oleic acid with respect to animals treated with oleic acid or cyclodextrin. In the case of medulla oblongata this bioamine shows a decrease in the group administered with cyclodextrin + oleic acid when compared with the group to which only cyclodextrin was administered. However, an opposite effect was seen in the same brain region when this group was compared with the oleic acid group (Fig. 1).

\section{Levels of dopamine \\ Adult animals}

The increase in the concentration of dopamine observed in the experimental groups was three times higher than what was seen in the control group. Comparison among the treated groups unveiled significantly lower level in the concentration of this bioamine in cyclodextrin + oleic group with regard to those treated with only oleic or cyclodextrin.

\section{Young animals}

With the exception of cerebellum/medulla oblongata, the levels of dopamine showed no differences among the experimental groups. In this region however, differences in the levels of this bioamine between the group treated with oleic acid and the control group was not observed. Nevertheless, when the group that received cyclodextrin is compared with the administration of oleic acid + cyclodextrin, there was an increase in the level of dopamine (Fig. 2).

\section{Levels of GSH \\ Adult animals}

Glutathione concentration showed significantly higher level in the control group to the tune of 8 -folds when compared with the experimental groups. In the cortex, the group with administration of cyclodextrin depicted a significantly lower concentration with respect to the 


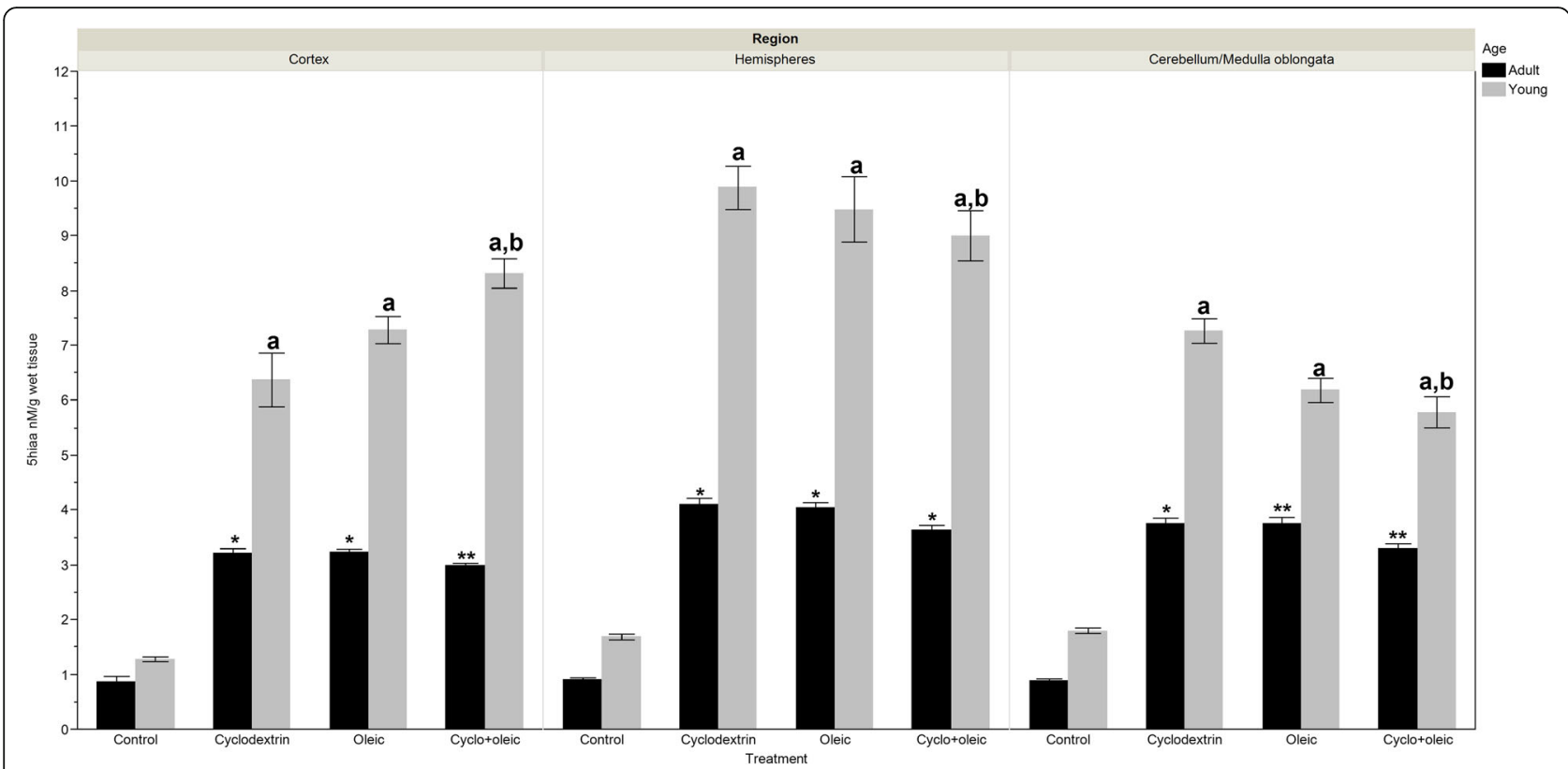

Fig. 1 Levels of 5-hydroxyindol acetic acid (5-HIAA) in brain regions of adult and young Wistar rats treated with oleic acid and cyclodextrin. Adult rat. Cortex: Anova $\mathrm{F}=240.29 p<0.0001$. $\left.^{*}\right) p<0.0001$ vs control, $\left.{ }^{* *}\right) p=0.047$ vs Oleic. Hemispheres: Kruskal-Wallis $\left.X^{2}=41.57 p<0.0001 .{ }^{*}\right) p<0.0001$ vs control, $\left.{ }^{* *}\right) p=0.026$ vs Cyclodextrin. Cerebellum/ Medulla Oblongata: Kruskal-Wallis $X^{2}=43.39 p<0.0001$. a) $p<0.0001$ vs control, **) $p=0.013$ vs Oleic and $p=0.009$ vs CyclodextrinYoung rat. Cortex: Kruskal-Wallis $X^{2}=47.54 p<0.0001$. a) $p<0.0001$ vs control, a,b) $p=0.039$ vs Oleic, and $p=0.017$ vs Cyclodextrin. Hemispheres: Kruskal-Wallis $X^{2}=42.07 p<0.0001$. a) $p<0.0001$ vs control. Cerebellum/medulla oblongata: Kruskal-Wallis $X^{2}=49.75 p<0.0001$. a) $p<0.0001$ vs control, a,b) $p<0.04$ vs Cyclodextrin

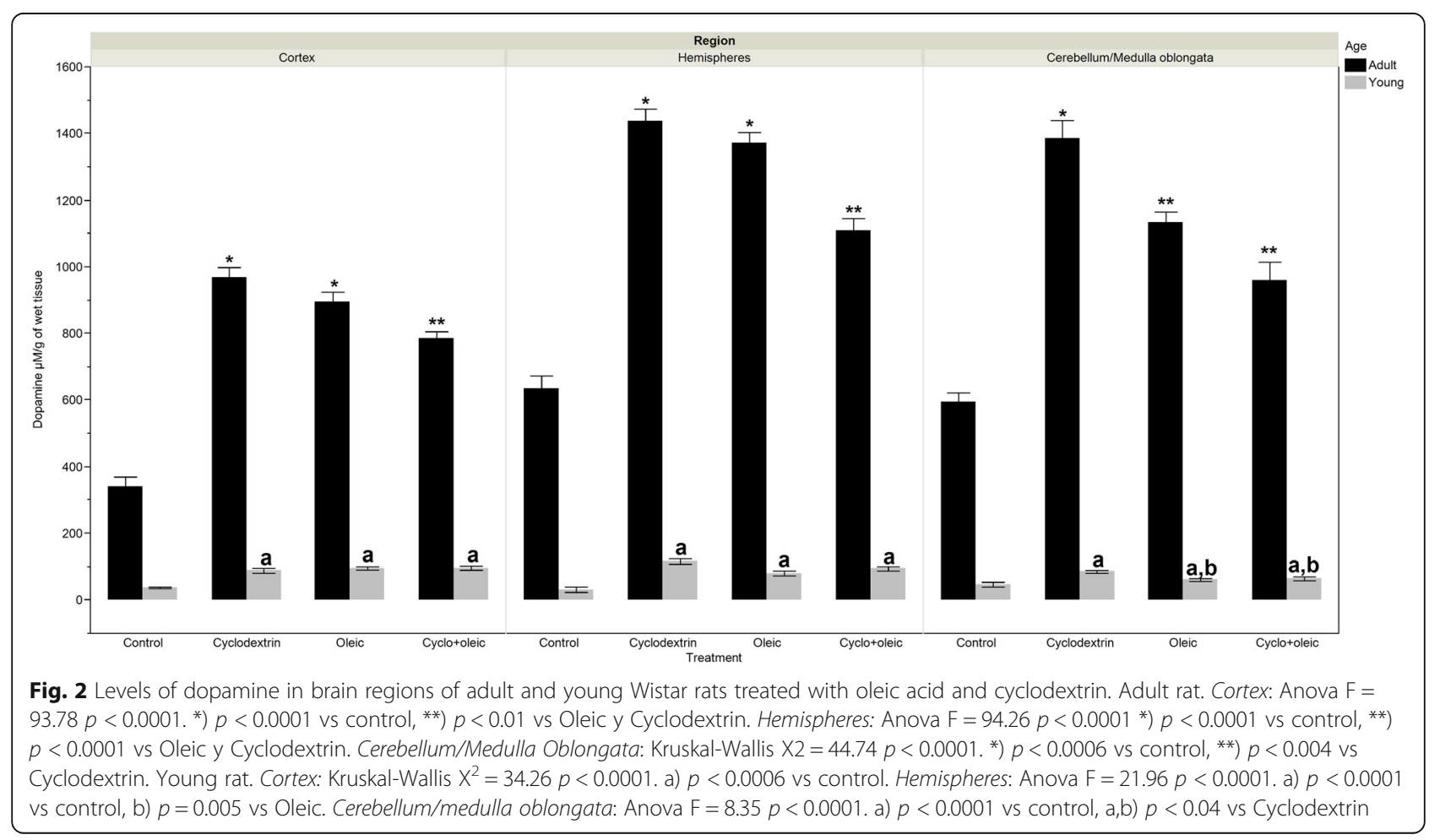


group that received cyclodextrin + oleic acid. In hemispheres and cerebellum/medulla oblongata, the concentration of this indicator portrayed no significant differences.

\section{Young animals}

The concentration of glutathione was higher in the control group with respect to the experimental groups. However, this was slightly significant in the cortex for the group treated with only cyclodextrin and cyclodextrin + oleic acid and in the hemisphere for the group that received oleic acid and cyclodextrin + oleic acid while in the cerebellum/medulla oblongata, the slight difference was seen in all the experimental groups. The comparison among the experimental groups revealed significant decrease of this indicator in cortex of the groups treated with only cyclodextrin and cyclodextrin + oleic acid with respect to the group that received only oleic acid. In the hemisphere, when the groups with oleic acid and cyclodextrin + oleic acid were contrasted with the group that received only cyclodextrin, the level of this indicator did not reach statistical difference (Fig. 3).

\section{Levels of Tbars}

\section{Adult animals}

The increase in the levels of Tbars in all the experimental groups with respect to the control group had statistically significant differences. In the three regions and in cyclodextrin + oleic group, the concentration of Tbars resulted to be significantly less when compared with only oleic or cyclodextrin group.

\section{Young animals}

There is an increase in the levels of Tbars in all the experimental groups when compared with the control group. Nevertheless, this was statistically significant in the three brain regions for the groups treated with oleic acid and cyclodextrin. In the group that received only cyclodextrin, significant differences were not appreciated when compared with the control however, the concentration of Tbars resulted to be less significant when weighed against the group that received only oleic in the cortex and cyclodextrin + oleic in cerebellum/medulla oblongata (Fig. 4).

\section{Levels of $\mathrm{H}_{2} \mathrm{O}_{2}$}

Adult animals

As was observed with GSH, the levels of $\mathrm{H}_{2} \mathrm{O}_{2}$ were significantly higher in the control group when compared with the experimental groups. In the cortex, the group with the administration of cyclodextrin + oleic displayed a significantly lower level with regard to the group that received only oleic. In the hemispheres, significant differences were not observed among the experimental groups. In cerebellum/medulla oblongata region, the levels of $\mathrm{H}_{2} \mathrm{O}_{2}$ were significantly higher in the group treated with only cyclodextrin in comparison with the group with administration of only oleic.

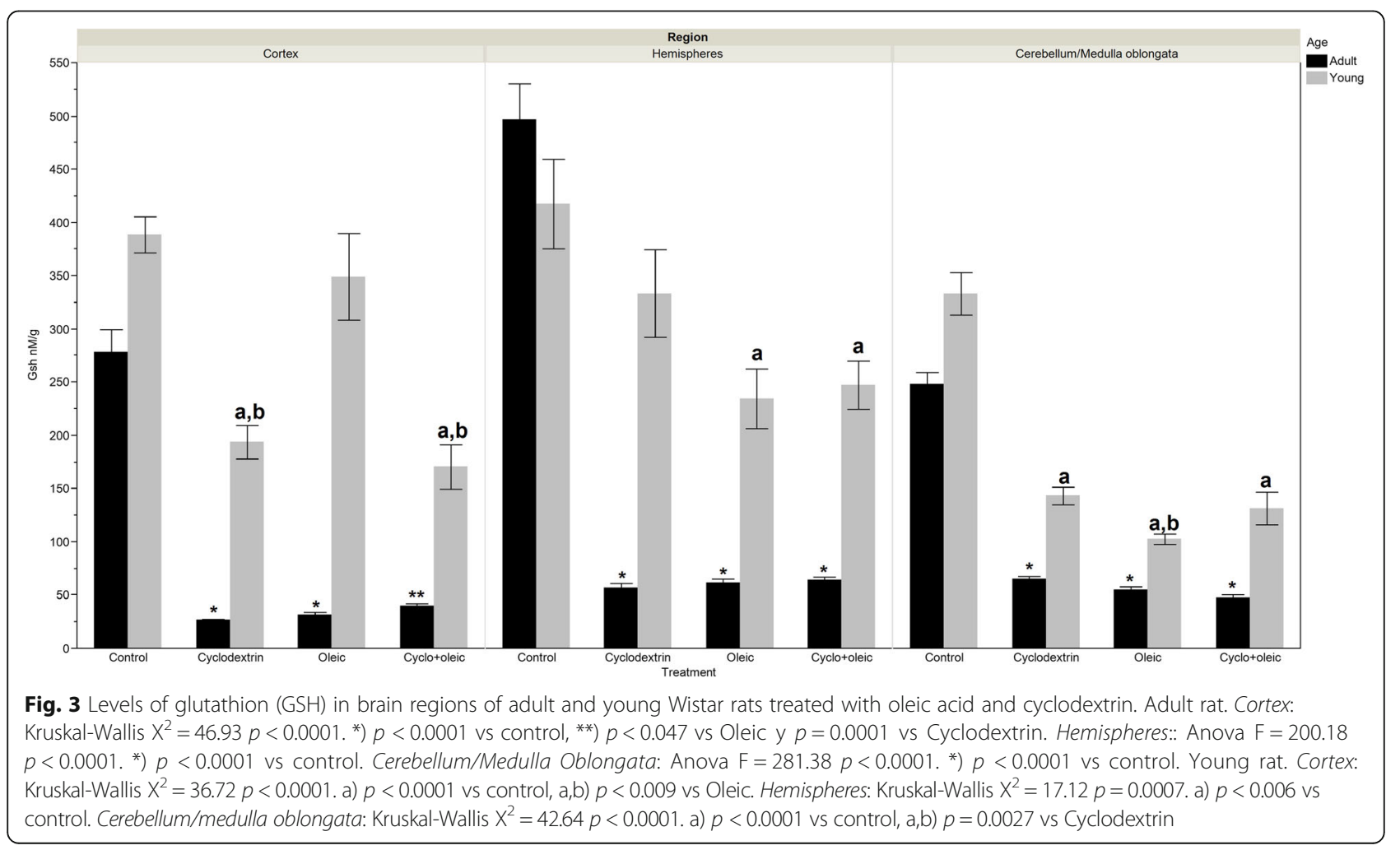




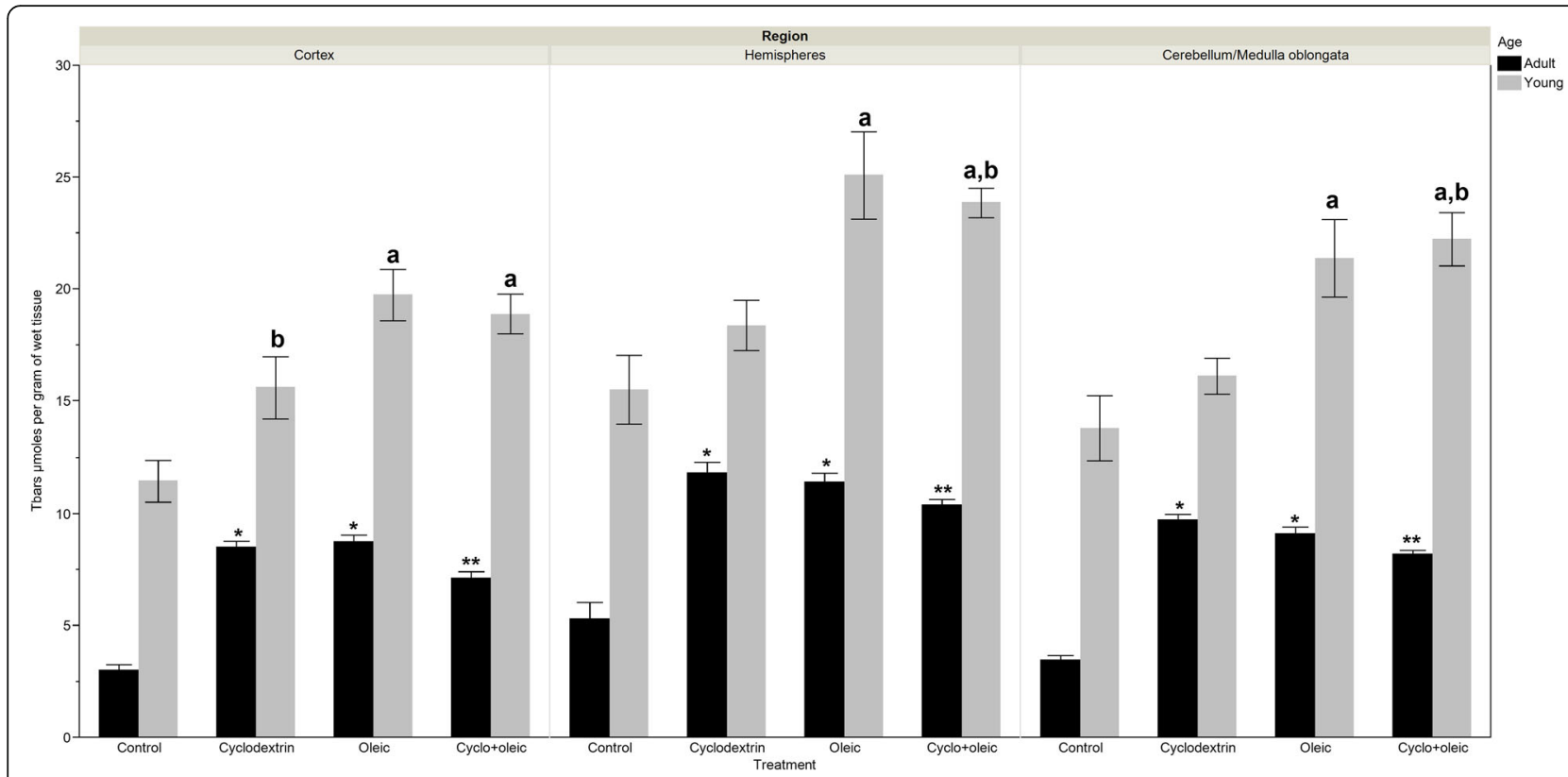

Fig. 4 Levels of Tbars (lipid peroxidation) in brain regions of adult and young Wistar rats treated with oleic acid and cyclodextrin. Adult rat. Cortex: Anova F $\left.=76.29 p<0.0001 .^{*}\right) p<0.0001$ vs control, $\left.{ }^{* *}\right) p=0.0002$ vs Oleic and $p=0069$ vs Cyclodextrin. Hemispheres: Kruskal-Wallis $X^{2}=28.17$ $\left.p<0.0001 .{ }^{*}\right) p<0.0015$ vs control, $\left.{ }^{* *}\right) p=0.002$ vs Cyclodextrin. Cerebellum/medulla oblongata: Anova $\mathrm{F}=115.37 p<0.0001$. $\left.{ }^{*}\right) p<0.0001$ vs control, *) $p=0.031$ vs Oleic y $p=0.0003$ vs Cyclodextrin. Young rat. Cortex: Anova $\mathrm{F}=10.68 p<0.0001$. a) $p<0.0002$ vs control, b) $p=0.04$ vs Oleic. Hemispheres: Kruskal-Wallis $X^{2}=21.69 p<0.0001$. a) $p<0.01$ vs control, b) $p=0.011$ vs Cyclodextrin. Cerebellum/medulla oblongata: KruskalWallis $X^{2}=22.63 p<0.0001$. a) $p<0.003$ vs control, b) $p=0.003$ vs Cyclodextrin

\section{Young animals}

As was observed with GSH, the levels of $\mathrm{H}_{2} \mathrm{O}_{2}$ were significantly higher in the control group with respect to the experimental groups although in the cortex, only the group treated with only cyclodextrin showed concentrations significantly less when compared with the control. Among the experimental groups, the levels of $\mathrm{H}_{2} \mathrm{O}_{2}$ in the cortex were significantly less in the group that received only cyclodextrin in comparison with the other groups. In cerebellum/medulla oblongata, the increase in $\mathrm{H}_{2} \mathrm{O}_{2}$ observed in the group with administration of cyclodextrin + oleic was thrice higher than what was seen in the other experimental groups and twice as that of control group (Fig. 5).

\section{Activity of ATPase \\ Adult animals}

The activity of this enzyme showed a decrease in the cortex of animal groups that received cyclodextrin + oleic acid with respect to the control group and animal group treated with only oleic acid. On the contrary, an increase in the activity of the enzyme was seen in the cerebellum/medulla oblongata of the control and oleic groups while in hemisphere, no significant differences were observed.

\section{Young animals}

The increase in the activity of this enzyme was twice bigger in the experimental groups when compared with the control. Among the groups that received the different treatments, significant differences were not observed (Fig. 6).

\section{Discussion}

Methyl $\beta$-cyclodextrin, which promotes cholesterol depletion in cell membranes in brain [22], increased dopamine and 5-HIAA amines in brain of young rats while, compared with adult animals the concentration of 5HIAA decreases. This may be owed to the fact that changes in cholesterol concentration in the plasma membrane of presynaptic nerve terminals lead to nonspecific modulation of amine transports and homeostasis in the central nervous system [23].

CDs are a group of nontoxic oligosaccharides with 6 glucose subunits that are widely used as drug excipients and protein stabilizers. They come as a mixture of isomers with various degrees and pattern of hydroxypropylation [24]. Probably these isomers induced the increase of lipoperoxidation and lower levels of GSH in the brain regions and hence loss of cell viability for the inability to suppress oxidative stress. Also, CDs forms a hydrophobic central cavity that binds lipids which in animal studies and in previous clinical trials has been shown to alter plasma lipid 

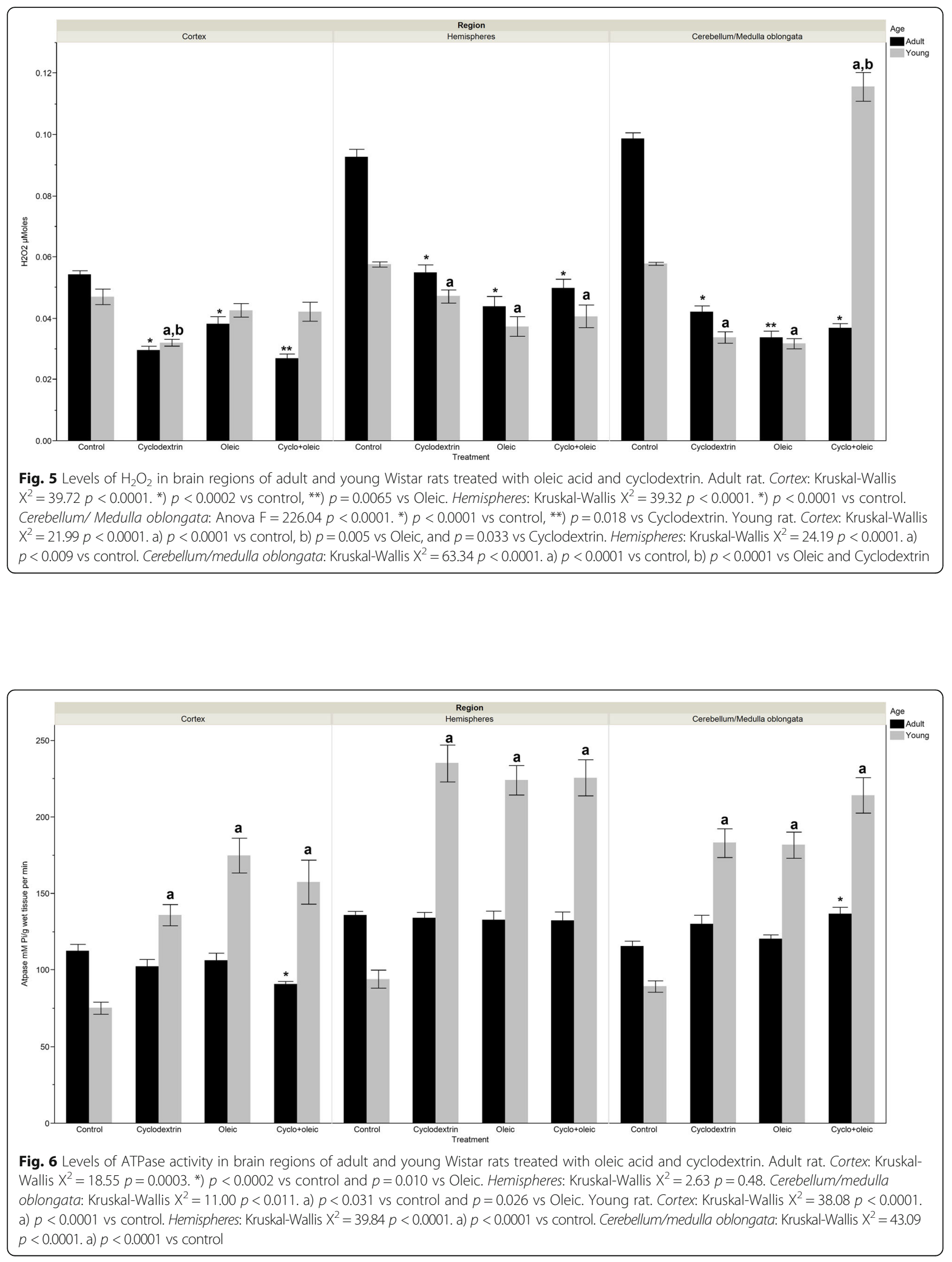
levels [25], and membrane fluidity [26]. Moreover, such hydrophobic cavity has been linked with induction of an increase in the ATPase activity in cortex and hemisphere regions of young animals, and a decrease in adult animals. In fact, the oxidative damage was more evident in adult animals, probably because brain aging is accompanied by a decrease in mitochondrial function [5].

The present study was made in demand for evidence-based recommendations for the use of antioxidants in the prevention and treatment of pediatric ailments.

\section{Conclusion}

The results suggest that the combination of high doses of oleic acid and $\beta$-cyclodextrin seems unsafe for healthy young and adult subjects for the fact that it induces an increase in dopamine and 5-HIAA amines. Oxidative damage may be the end result of this effect.

\section{Abbreviations}

5-HIAA: 5-hydroxyindoleacetic acid; BCD: $\beta$-cyclodextrin; CDs: Cyclodextrins; CNS: Central nervous system; DNA: Deoxyribonucleic acid; GSH: Glutathione; HClO4: Perchloric acid; NOGSH: Nitroso-glutathione; OA: Oleic acid; R-LA: R-alipoic acid; RNS: Reactive nitrogen; ROS: Reactive oxygen;

Tbars: Thiobarbituric acid reactive substances

\section{Acknowledgments}

We thank Dr. Cyril Ndidi Nwoye a native English speaker and language professor, for the critical review and translation of this manuscript.

\section{Funding}

This research received no specific grant from any funding agency in the public, commercial, private, or not-for-profit sectors.

\section{Availability of data and materials}

The datasets used and/or analyzed during the current study are available from the corresponding author on reasonable request.

\section{Authors' contributions}

DCG, HJO Contributed to conception and design. DCG, NOB, MOH, GBM, $\mathrm{HJO}$, AVP Contributed to acquisition, analysis, or interpretation of data. DCG, $\mathrm{NOB}, \mathrm{MOH}, \mathrm{GBM}, \mathrm{AVP}$ Critically revised the manuscript for important intellectual content. DCG, HJO Drafted manuscript. DCG, NOB, MOH, GBM, HJO, AVP Gave final approval.

\section{Ethics approval}

This study was approved in our institution by The Committee For The Animal Protection. Besides, all experimental procedures were carried out under the rules of the Laboratory Animals Use and Care Committee of international institutions.

\section{Consent for publication}

Our manuscript does not contain data from any individual person, then is not applicable.

\section{Competing interests}

The authors declare that they have no competing interests.

\section{Publisher's Note}

Springer Nature remains neutral with regard to jurisdictional claims in published maps and institutional affiliations.

\section{Author details}

'Laboratorio de Neuroquímica, Instituto Nacional de Pediatría (INP), Mexico City, Mexico. ${ }^{2}$ Laboratorio de Bacteriología Experimental, INP, Mexico City, Mexico. ${ }^{3}$ Laboratorio de Farmacología, INP. Facultad de Medicina,
Universidad Nacional Autónoma de México, Avenida Imán N 1, 3rd piso Colonia Cuicuilco CP, 04530 Mexico City, Mexico.

Received: 19 February 2018 Accepted: 9 July 2018

Published online: 25 July 2018

\section{References}

1. Volmer DA, Qi Y. $\beta$-Cyclodextrin affects the formation of isomerization products during peptide deamidation. Eur J Mass Spectrom. 2015;21:701-5.

2. Vecsernyés M, Fenyvesi F, Bácskay I, Deli MA, Szente L, Fenyvesi E. Cyclodextrins, blood-brain barrier, and treatment of neurological diseases. Arch Med Res. 2014;45:711-29.

3. Rami A, Ferger D, Krieglstein J. Blockade of calpain proteolytic activity rescues neurons from glutamate excitotoxicity. Neurosci Res. 1997;27:93-7.

4. Aliev G, Obrenovich ME, Tabrez S, Jabir NR, Reddy VP, Li Y, et al. Link between cancer and Alzheimer disease via oxidative stress induced by nitric oxide-dependent mitochondrial DNA overproliferation and deletion. Oxidative Med Cell Longev. 2013;962984:1-19. https://doi.org/10.1155/2013/ 962984.

5. Schloesser A, Esatbeyoglu T, Piegholdt S, Dose J, Ikuta N, Okamoto H, et al. Dietary tocotrienol/ $Y$-cyclodextrin complex increases mitochondrial membrane potential and ATP concentrations in the brains of aged mice. Oxid Med Cel Longev. 2015;789710:1-8.

6. Ikuta N, Okamoto H, Furune T, Uekaji Y, Terao K, Uchida R, et al. Bioavailability of an R-a-lipoic acid/ $Y$-cyclodextrin complex in healthy volunteers. Int J Mol Sci. 2016:17:6.

7. Hogg N, Singh RJ, Kalyanaraman B. The role of glutathione in the transport and catabolism of nitric oxide. FEBS Let. 1996;382:223-8.

8. Beckman JS, Beckman TW, Chen J, Marshall PA, Freeman BA. Apparent hydroxyl radical production by peroxynitrite: implications for endothelial injury from nitric oxide and superoxides. Proc Natl Acad Sci U S A. 1990;87: 1624-9.

9. Gutteridge JM, Halliwell B. The measurement and mechanism of lipid peroxidation in biological systems. Trends Biochem Sci. 1990;15:129-35.

10. Driver AS, Kodavanti PR, Mundy WR. Age-related changes in reactive oxygen species production in rat brain homogenates. Neurotoxicol Teratol. 2000:22:175-81.

11. Browne SE, Beal MF. Oxidative damage in Huntington's disease pathogenesis. Antioxid Redox Signal. 2006:8:2061-73.

12. Swapna I, Sathya KV, Murthy CR, Senthilkumaran B. Membrane alterations and fluidity changes in cerebral cortex during ammonia intoxication. NeuroToxicology. 2005;335:700-4

13. Stefanello FM, Chiarani F, Kurek AG. Methionine alters $\mathrm{Na}^{+}, \mathrm{K}^{+}$ATPase activity, lipid peroxidation and nonenzymatic antioxidant defences in rat hippocampus. Int J Dev Neurosc. 2005;23:651-6.

14. Calderón-Guzmán D, Espitia-Vázquez I, López-Domínquez A, et al. Effect of toluene and nutritional status on serotonin, lipid peroxidation levels and $\mathrm{Na}^{+} / \mathrm{K}^{+}$ATPase in adult rat brain. Neurochem Res. 2005:30:619-24.

15. Calderón-Guzmán D, Osnaya-Brizuela N, García-Alvarez R, Hernández García E, Guillé-Pérez A, Juárez OH. Levels of glutathione and some biogenic amines in the human brain putamen after traumatic death. Proc West Pharmacol Soc. 2008;51:25-32.

16. Beck O, Palmskog G, Hultman E. Quantitative determination of 5-hydroxyindole3-acetic acid in body fluids by HPLC. Clin Chim Acta. 1977;79:149-54.

17. Hissin PJ, Hilf R. A flurometric method for determination of oxidized and reduced glutathione in tissue. Anal Biochem. 1974;4:214-26.

18. Calderon $\mathrm{GD}$, Juarez $\mathrm{OH}$, Hernandez $\mathrm{GE}$, et al. Effect of an antiviral and vitamins $A, C, D$ on dopamine and some oxidative stress markers in rat brain exposed to ozone. Arch Biol Sci Belgrade. 2013:65:1371-9.

19. Fiske $\mathrm{CH}$, Subbarow $\mathrm{Y}$. The colorimetric determination of phosphorus. J Biol Chem. 1925:66:375-400

20. Asru KS. Colorimetric assay of catalase. Anal Biochem. 1972;47:389-94.

21. Castilla-Serna L. Practical statistical guide for health science. Editorial Trillas. $1{ }^{\circ}$ Edición. México, D.F. 2011.

22. Garcia DG, de Castro-Faria-Neto HC, da Silva Cl, et al. Na/K-ATPase as a target for anticancer drugs: studies with perillyl alcohol. Mol Cancer. 2015; 14:105. https://doi.org/10.1186/s12943-015-0374-5.

23. Horák D, Beneš M, Procházková Z, et al. Effect of O-methyl- $\beta$-cyclodextrinmodified magnetic nanoparticles on the uptake and extracellular level of I-glutamate in brain nerve terminals. Colloids Surf B-Biointerfaces. 2016;149:64-71. 
24. Malanga M, Szemán J, Fenyvesi E, et al. Back to the Future: A new look at hydroxypropyl Beta-cyclodextrins. J Pharm Sci. 2016;105(9):2921-31.

25. Amar MJ, Kaler M, Courville AB, Shamburek R, Sampson M, Remaley AT. Randomized double blind clinical trial on the effect of oral a-cyclodextrin on serum lipids. Lipids Health Dis. 2016;15:115.

26. Korinek M, Vyklicky V, Borovska J, et al. Cholesterol modulates open probability and desensitization of NMDA receptors. J Physiol. 2015;593: 2279-93.

Ready to submit your research? Choose BMC and benefit from:

- fast, convenient online submission

- thorough peer review by experienced researchers in your field

- rapid publication on acceptance

- support for research data, including large and complex data types

- gold Open Access which fosters wider collaboration and increased citations

- maximum visibility for your research: over $100 \mathrm{M}$ website views per year

At $\mathrm{BMC}$, research is always in progress.

Learn more biomedcentral.com/submissions 